\title{
ENSINANDO PROBABILIDADE EXPLORANDO AS LOTERIAS
}

\section{TEACHING PROBABILITY EXPLORING THE LOTTERIES}

\author{
Maria Iara Brito e Silva ${ }^{1}$ \\ Universidade Estadual Vale do Acaraú \\ Carina Brunehilde Pinto da Silva ${ }^{2}$ \\ Universidade Estadual Vale do Acaraú
}

\section{Resumo}

Os jogos de azar sempre estiveram presentes na vida do homem, sendo inclusive um dos principais motivadores dos primeiros estudos em probabilidade. Nesse contexto, o presente trabalho tem como objetivo detalhar o projeto Ensinando probabilidade explorando as loterias, desenvolvido pelos bolsistas do subprojeto de matemática do Programa Institucional de Bolsas de Iniciação à Docência (PIBID) vinculado à Universidade Estadual Vale do Acaraú (UVA), direcionado aos alunos do $2^{\circ}$ ano do Ensino Médio do colégio estadual Dom José Tupinambá da Frota. O projeto foi desenvolvido como forma de melhorar o desempenho dos alunos nas aulas de matemática a partir de uma situação do cotidiano. Para tanto, foi escolhido trabalhar com os jogos de azar, especificamente a mega-sena, visto a popularidade desse jogo na cultura brasileira. O contato direto dos alunos com algo pertencente a sua realidade despertou o interesse destes para o conteúdo estudado, alcançando os objetivos do projeto. O maior interesse dos alunos estava voltado para a justiça ou a injustiça das apostas, dúvida que surgiu quando foi exposta a tabela de preços para comparação dos valores cobrados por cada dezena apostada. Também foi mostrado como são feitas as apostas e a distribuição dos prêmios. No decorrer da oficina, foi trabalhada a habilidade de interpretação de questões pelos alunos e a resolução de problemas que envolvem este conteúdo, como a chance de ganhar na loteria de acordo com a aposta e a comparação do aumento do valor e das chances de ganhar.

Palavras-chave: Ensino de Probabilidade; Educação; Jogos.

\begin{abstract}
Gambling has always been present in man's life and has been one of the main motivators of early probability studies. In this context, the present work aims to detail the project Teaching probability by exploring lotteries, developed by scholars of the Mathematics subproject of the Institutional Program of Initiation to Teaching (Pibid) linked to the Universidade Estadual Vale do Acaraú (UVA), aimed at students of the second year of high school at the state school Dom José Tupinambá da Frota. The project was developed as a way to improve students' performance in math classes based on a daily situation. For that, it was chosen to work with games of chance, specifically mega-sena, given the popularity of this game in Brazilian culture. The direct contact of students with something belonging to their reality aroused their interest for the content
\end{abstract}

\footnotetext{
${ }^{1}$ Email: iaratudes15@gmail.com

${ }^{2}$ E-mail: profcarinamat@yahoo.com.br
} 
studied reaching the objectives of the project. Being that the greater interest of the students was in the justice or injustice of the bets, doubt that came when it was exposed to the price list for comparison of the values charged by each ten bet. It was also shown how the bets and the distribution of the prizes are made. Throughout the workshop, students' ability to interpret questions and solve problems involving this content, such as the chance to win the lottery according to the bet and the comparison of the increase in value and the chances of winning, were worked out.

Keywords: Teaching of Probability; Education; Games.

\section{Introdução}

Probabilidade é uma palavra de origem latina derivada de probare (provar ou testar), surgida na Idade Média, a partir do interesse do homem em estudar os fenômenos que envolviam jogos de azar, sendo suas primeiras teorias desenvolvidas pelos matemáticos Luca Pacioli, Girolano Cardano, Galileu Galilei e Niccolo Tartaglia, que despertaram o interesse por esse estudo através da curiosidade em descobrir o próximo número em um lançamento de dado.

Luca Pacioli (1500) solucionou o Problema dos pontos, para o qual foi feita uma divisão correspondente à probabilidade de vitória de cada jogador. Girolano Cardano (1526) foi o primeiro a introduzir técnicas de combinação no cálculo da probabilidade em eventos aleatórios, além de ser o autor da que é considerada como a primeira obra conhecida sobre o estudo de probabilidades, o livro De Ludo Aleae (Sobre Jogos de Azar). Galileu Galilei (1556), no livro Considerações sobre os jogos de dados, mostrou que, apesar de a probabilidade da soma no lançamento de 3 dados ser igual a 9 ou 10 serem equivalentes, o resultado 10 é mais comum quando comparado ao 9. Niccolo Tartaglia (1590) dedicou páginas do seu livro General Trattato aos problemas de Pacioli. (MORGADO, 1997).

Segundo Boyer (1996), o estudo mais aprofundado da probabilidade em seus casos mais complexos foi explorado pelos matemáticos Blaise Pascal e Pierre de Fermat. O fascínio de Pascal pela probabilidade surgiu pela curiosidade de um filósofo interessado em jogos, chamado Chevalier de Maré, em saber como deveria ser indenizado um jogador que "em oito lances de um dado deve lançar um, mas depois de três tentativas infrutíferas o jogo é interrompido”. Com dúvidas, Chevalier de Maré pede ajuda a Pascal, que, junto ao matemático Pierre de Fermat, decide buscar respostas às perguntas indagadas pelo mesmo. Esse assunto era algo novo para os matemáticos da 
época, que passaram a buscar respostas para o acaso dos jogos, tornando-se os matemáticos responsáveis por começar a estabelecer formalizações da teoria da probabilidade e a desenvolvê-la mais fortemente como ciência.

Iniciada por levantamento de hipótese envolvendo possíveis resultados para o lançamento de dados, hoje a probabilidade faz-se muito importante, sendo indispensável no estudo de diversas áreas, como em estatística, economia, engenharia, física, psicologia, biologia, entre outros ramos do conhecimento.

Os jogos de azar representam um dos principais motivos para o início da teoria da probabilidade. Lima (2006) afirma que "O interesse dos matemáticos no estudo sistemático de probabilidades é relativamente recente e tem suas raízes no estudo dos jogos de azar." De fato esses jogos são assuntos recorrentes desde os primeiros livros publicados e sempre estiveram presentes na vida do homem, possuindo registros arqueológicos há 40.000 anos, sendo o mais antigo e conhecido o jogo do osso, surgindo depois, na Mesopotâmia, por volta de 3000 a. C., os jogos de dados.

Sendo a Matemática uma ciência de grande importância, pois está presente em diversas situações do dia a dia, e sendo a probabilidade um de seus ramos com maior aplicabilidade às atividades humanas, é fundamental o desenvolvimento de diferentes mecanismos que possibilitem a potencialização do aprendizado dos alunos da educação básica no que diz respeito aos principais conceitos desta ciência.

A intuição, muitas vezes, leva a "falsas certezas" e os jogos de loteria são um bom exemplo disso, como será mostrado ao longo deste trabalho. O estudo da probabilidade auxilia a identificar as chances de cada jogador ser o ganhador do prêmio ao realizar uma aposta e sua relação com a quantidade de números apostados.

Nas loterias, as apostas são feitas pelos jogadores que selecionam os números de forma arbitrária, os quais serão registrados na cartela oficial. As quantidades de números e premiações dependerão da categoria. No Brasil, existem 10 tipos de modalidades administradas pela Caixa Econômica Federal, que são: loteria federal, mega-sena, lotofácil, quina, lotomania, dupla-sena, timemania, loteca, lotogol e loteria instantânea; sendo a mais popular, conhecida também por seus prêmios milionários, a mega-sena, a qual se tornou o modelo mais apostado. 
A mega-sena, criada em março de 1996, atualmente é a que tem a premiação mais valiosa. Para apostar nessa modalidade, o jogador poderá marcar uma quantidade de seis números pelo valor de 3,50 e, quanto maior a quantidade de números marcados, maior será o valor da aposta, aumentando também as chances de vitória.

Com o passar dos anos, a mega-sena tem se aperfeiçoado com o aumento do valor de suas apostas e até mesmo o aumento do número de dezenas a serem apostadas. Também foi criada, no ano de 2009, a Mega-sena da Virada, que é um sorteio feito no último dia do ano, cuja premiação corresponde a 5\% de todas as apostas feitas no decorrer do ano.

Tabela 1 - Preço por dezena apostada

\begin{tabular}{ccccc}
\hline $\begin{array}{c}\text { Quantidade } \\
\text { de números } \\
\text { jogados }\end{array}$ & $\begin{array}{c}\text { Valor de } \\
\text { aposta }\end{array}$ & Sena & Quina & Quadra \\
\hline 6 & 3,50 & 50.063 .860 & 154.518 & 2.332 \\
\hline 7 & 24,50 & 7.151 .980 & 44.981 & 1.038 \\
\hline 8 & 98,00 & 1.787 .995 & 17.192 & 539 \\
\hline 9 & 294,00 & 595.998 & 7.791 & 312 \\
\hline 10 & 735,00 & 238.399 & 3.973 & 195 \\
\hline 11 & $1.617,00$ & 108.363 & 2.211 & 129 \\
\hline 12 & $3.234,00$ & 54.182 & 1.317 & 90 \\
\hline 13 & $6.006,00$ & 29.175 & 828 & 65 \\
\hline 14 & $10.510,50$ & 16.671 & 544 & 48 \\
\hline 15 & $17.517,50$ & 10.003 & 370 & 37 \\
\hline
\end{tabular}

Fonte: Caixa Econômica Federal (2016)

Quanto à premiação, o prêmio bruto corresponde a 45,3\% da arrecadação, já computado o adicional destinado ao Ministério do Esporte. Dessa porcentagem: 35\% são distribuídos entre os acertadores dos 6 números sorteados (Sena); 19\% entre os acertadores de 5 números (Quina); 19\% entre os acertadores de 4 números (Quadra); $22 \%$ ficam acumulados e são distribuídos aos acertadores dos 6 números nos concursos de final 0 ou 5; $5 \%$ ficam acumulados para o sorteio de fim do ano (Mega da Virada). 
Conhecendo a ligação que a probabilidade tem com os jogos de loterias, foi criada uma oficina que tratou da exploração destas nas aulas de matemática, estudando a grande diferença entre a probabilidade de ganhar na mega-sena, dependendo da quantidade apostada, e o porquê do valor das apostas mudar tanto.

A partir do exposto, a oficina Ensinando probabilidade explorando as loterias tem como objetivo auxiliar no entendimento de conceitos básicos de probabilidade. Os alunos aprendem o conteúdo de forma dinâmica, algo diferenciado do que eles estão acostumados nas aulas tradicionais, já que, além da explicação e da resolução de exercícios, o aprendizado também se dá por meio de brincadeiras.

No entanto, o objetivo principal da oficina não é simplesmente a forma lúdica de ensino, mas a percepção de que a probabilidade é facilmente aplicada às mais diversas situações do cotidiano.

\title{
Referencial teórico
}

Uma grande parte dos conteúdos da matemática do Ensino Médio está relacionada a situações cotidianas. O papel do professor ao abordar esses assuntos, segundo os PCN (Parâmetros Curriculares Nacionais), será ajudar a estruturar o pensamento e o raciocínio dedutivo para que os alunos consigam relacionar o conteúdo estudado a dificuldades encontradas na realidade, além de ajudar a resolvê-las.

\begin{abstract}
A Matemática no Ensino Médio tem um valor formativo, que ajuda a estruturar o pensamento e o raciocínio dedutivo, porém também desempenha um papel instrumental, pois é uma ferramenta que serve para a vida cotidiana e para muitas tarefas específicas em quase todas as atividades humanas. (BRASIL, 2000, p.40).
\end{abstract}

A explicação de conteúdos usando exemplos práticos é uma estratégia que facilita a compreensão dos alunos, já que estarão resolvendo problemas já vivenciados por eles ou por alguém à sua volta. Por conhecerem essa realidade, eles têm entendimento de como funciona, sendo necessário apenas aprender como resolvê-los.

Abordar situações do cotidiano nas aulas de matemática faz com que os alunos reconheçam a importância do estudo da disciplina, de modo que possam compreender que cada conteúdo presente nas aulas está exposto em determinados momentos de seu 
dia a dia, mas que dificilmente eles conseguem percebê-lo. Essa falta de reconhecimento da aplicabilidade da matemática em suas atividades, pois em muitos casos os alunos não conseguem conciliar o conteúdo aprendido com algum problema cotidiano, leva-os a concluir, equivocadamente, que a disciplina é algo insignificante e sem relevância.

O objetivo do professor ao aplicar um jogo na ministração de suas aulas é que os alunos compreendam o conteúdo e saibam como resolver situações não só em sala de aula, mas fora dela também, pois a partir do uso do jogo o docente poderá elaborar problemas que relacionam o jogo usado, a situações do cotidiano.

\begin{abstract}
Ao optar pelo jogo como estratégia de ensino, o professor o faz com uma intenção: propiciar a aprendizagem. $\mathrm{E}$ ao fazer isto tem como propósito o ensino de um conteúdo ou de uma habilidade. Dessa forma, o jogo escolhido deverá permitir o cumprimento deste objetivo. O jogo para ensinar Matemática deve cumprir o papel de auxiliar no ensino do conteúdo, propiciar a aquisição de habilidades, permitir o desenvolvimento operatório do sujeito e, mais, estar perfeitamente localizado no processo que leva do conhecimento primeiro ao conhecimento elaborado (MOURA, 1992, p. 47).
\end{abstract}

Segundo Grando (1995), jogos pedagógicos são aqueles que podem ser utilizados no processo de ensino-aprendizagem, exemplos disso são os jogos de azar, cuja principal característica é a de que o jogador não tem como interferir ou alterar na solução, ou seja, depende do acaso para vencer. Exemplos deles são: par ou ímpar, cassinos e loterias. Portanto, o jogo de mega-sena pode ser incluído entre os jogos pedagógicos, uma vez que a aleatoriedade dos resultados constitui uma possível técnica para explicar probabilidade, que, segundo os PCN (BRASIL, 2000), juntamente com a análise combinatória, é um assunto fundamental para explicar fenômenos naturais e aplicações da matemática em questões do mundo real, justificando, mais uma vez, a relevância deste trabalho.

\title{
Metodologia
}

A oficina Ensinando probabilidade explorando as loterias foi aplicada em dois encontros com dois grupos diferentes de alunos, os quais estavam cursando o segundo 
ano do Ensino Médio do colégio Estadual Dom José Tupinambá da Frota, escola atendida pelo Pibid, no turno vespertino nas turmas "G" e " $\mathrm{H}$ ".

Os encontros foram realizados na tarde do dia 26 de agosto de 2016, com duração de aproximadamente 1 hora e 30 minutos. Os alunos eram retirados de sala e transferidos para uma sala que não era utilizada no período da tarde. O primeiro e o segundo grupo participantes da oficina possuíam 10 e 8 alunos, respectivamente.

Cada encontro foi iniciado com algumas perguntas sobre o conhecimento dos alunos em relação ao conteúdo de probabilidade:

- Vocês lembram o que se estuda em probabilidade?

- Em qual ou quais situações do cotidiano de vocês é usada a probabilidade?

- $\quad$ Vocês conhecem este símbolo (!)?

- Vocês conhecem esta fórmula?

$$
C_{n, p}=\left(\begin{array}{l}
n \\
p
\end{array}\right)=\frac{n !}{p !(n-p) !}
$$

Depois foram discutidas as respostas dos alunos, após isto foi apresentado o tema da oficina e buscou-se saber o que eles conheciam sobre loterias e suas modalidades, bem como suas apostas, seus custeios e a distribuição do dinheiro arrecadado, principalmente sobre a mega-sena.

Após discussões iniciais sobre a mega-sena, buscou-se saber a opinião de cada um deles em relação aos valores cobrados pelas apostas, principalmente quanto ao aumento do preço do bilhete quando se aposta um número a mais. Foi apresentada a tabela de valores da Caixa Econômica Federal, no intuito de despertar a curiosidade dos alunos para a variação desses valores. Usando este gancho, a intenção foi discutir se o aumento do valor da aposta era equivalente ao aumento das chances de vitória à medida que se aumenta a quantidade de números apostados. Para possibilitar essa explicação, foi necessário relembrar o conceito de combinação, visto anteriormente nas aulas de análise combinatória.

A proposta foi que os alunos percebessem que, se o preço do bilhete ao se apostar seis dezenas é de $\mathrm{R} \$ 3,50$, será de $7 \times 3,50=\mathrm{R} \$ 24,50$ se marcado sete dezenas, pois embora o aumento seja de apenas um número, este dará 7 possibilidades de vitória 
para a qual antes só havia uma. Afinal, de um grupo de 6 dezenas só há uma maneira de escolher $6\left(\mathrm{C}_{6}{ }^{6}\right.$, combinação de 6 elementos 6 a 6$)$, enquanto que se houver 7 dezenas, então existirão 7 maneiras diferentes de selecionar 6 delas $\left(\mathrm{C}_{7}{ }^{6}\right.$, combinação de 7 elementos 6 a 6$)$.

Para que o estudo das loterias se tornasse mais interessante, foi simulado um jogo de mega-sena em que foram distribuídos bilhetes utilizados nas lotéricas e cada aluno poderia marcar como se estivesse fazendo a aposta máxima de $\mathrm{R} \$ 17.517,50$, que corresponde a uma aposta de 15 dezenas.

As apurações para saber o valor que seria arrecadado com suas supostas apostas foram realizadas com a ajuda dos próprios estudantes. Foram feitos também os cálculos para saber a distribuição desse dinheiro, quanto ficaria para quem acertasse a sena, a quina e a quadra, seguindo as informações de premiação contidas no site da Caixa Econômica Federal. Depois dos resultados encontrados, foi feito o sorteio das seis bolas, usando um bingo.

Posteriormente, foi pedido que os alunos fizessem o cálculo da probabilidade de eles ganharem no jogo feito por eles, uma aposta de 15 dezenas; depois, inspirando-se no cálculo feito para a aposta com sete dezenas, os estudantes fizeram o cálculo para saber se era justo ou injusto cobrar $\mathrm{R} \$ 17.517,50$ nesta aposta.

Depois que os alunos fizeram o cálculo e tiraram suas próprias conclusões, foilhes ensinado o cálculo da chance de ganhar na quina apostando seis e sete dezenas. Após isso, foi pedido que os alunos fizessem o cálculo da chance de eles acertarem a quadra nas suas apostas.

Para cada cálculo feito, a fim de explicitar a chance de acerto, sempre era calculada a porcentagem para reforçar o conhecimento dos alunos neste conteúdo.

\section{Resultados e discussão}

Após realizadas as primeiras perguntas relacionadas à probabilidade aos alunos, os mesmos se fizeram participativos, não somente durante as perguntas, mas no decorrer de toda a oficina. Todos os estudantes participantes da oficina tentavam dar uma 
resposta a cada pergunta feita. Vale ressaltar que o assunto não era novo para eles, visto que já tinha sido estudado nas aulas regulares.

Inicialmente, perguntou-se sobre o que os alunos se lembravam de probabilidade. Muitos responderam que não lembravam, outros tentavam lembrar e, os que lembraram, nos dois encontros, responderam que em probabilidade se estuda os arranjos, resposta bastante vaga. Foi impactante perceber este desconhecimento sobre o conteúdo, já que configurava um dos últimos estudados por eles, tendo, inclusive, sido cobrado na última avaliação parcial, feita uma semana antes da aplicação da oficina, o que significa que não fazia sequer um mês que tinham estudado probabilidade.

Quando foi pedido para que citassem situações do dia a dia que envolvem probabilidade, os estudantes conheciam muito bem e citaram: chance de ganhar nos jogos, tipo de cabelo, cor dos olhos. Aparentemente, na escola, os alunos tiveram contato com exemplos de situações do cotidiano durante as aulas.

Ao interrogar-lhes se conheciam o símbolo fatorial (!), todos responderam que o conheciam e qual a sua função quando aparece em um problema matemático.

Ao indagar-lhes sobre a fórmula, alguns dos alunos disseram que conheciam, outros responderam que não. Um aluno ainda disse: "Conhecer até que a gente conhece, difícil é saber usar.", sendo apoiado por alguns colegas na sua afirmação.

Sobre as perguntas feitas para saber qual o nível de conhecimento dos alunos em relação aos jogos de azar, sendo eles os jogos de loteria e, principalmente, a mega-sena, foi observado que todos conheciam vários jogos, apesar de nunca terem jogado. Por não fazerem apostas, não conheciam o valor cobrado por elas. Então foi dito quanto valeria cada jogo, dependendo da quantidade de dezenas apostadas, fato que despertou fortemente a estranheza nos alunos.

Foi possível constatar que, de fato, a utilização de jogos configura uma ótima estratégia pedagógica, ajudando a vincular conceitos às situações reais, ressignificando o aprendizado da matemática. A escolha dos jogos da loteria como motivadores da discussão também se mostrou acertada, pois sua ligação histórica com a probabilidade auxilia efetivamente no ensino do conteúdo, um dos objetivos fundamentais da utilização de jogos no ensino, conforme proposto por Moura (1992). 
A partir disso, surgiu a pergunta que buscava a opinião dos participantes da oficina: "Vocês consideram justo o aumento do valor de uma aposta ao se apostar um número a mais?". Todos responderam que o valor cobrado não é justo, pois é muito alto. Neste momento, foi explicado que, através da probabilidade, era possível provar se era justo ou injusto esse grande aumento do valor da aposta. Isso despertou o interesse deles para provar se realmente estavam certos em suas opiniões.

Para provar que o aumento era justo, optou-se pela simulação do jogo. Ao final do jogo realizado, nenhum dos participantes teve mais que três dezenas sorteadas.

Quando chegou o momento de calcular quais premiações corresponderiam à aposta feita por eles através do cálculo da porcentagem, os alunos sentiram uma grande dificuldade e sempre pediam auxílio, apesar de na lousa constarem alguns cálculos de porcentagem para que tomassem como exemplo.

Posteriormente, foi detalhada a fórmula que seria usada nos cálculos seguintes e alguns alunos sabiam a que correspondia cada letra da fórmula. No decorrer dos cálculos, fizeram-se participativos os dois grupos de alunos, mas foi percebido que alguns não sabiam fazer divisão e multiplicação de frações. Isso foi constatado quando os alunos foram desafiados a calcular em quanto aumentava a probabilidade de ganhar apostando sete dezenas se comparado à aposta com seis. $\mathrm{O}$ objetivo era que os alunos encontrassem uma razão entre as probabilidades referidas, o que levava à divisão de $7 / 50.063 .860$ por 1/50.063.860, um cálculo considerado simples, levando-se em conta a série e a idade dos alunos, acrescentando-se ainda o fato de os dois números possuírem o mesmo denominador, o que facilitaria ainda mais. Porém, as dificuldades foram grandes e, por vezes, os estudantes não souberam como calcular. As confusões que os alunos da educação básica apresentam com o uso de aritméticas simples é fato sabido culturalmente, na aplicação desta oficina não foi diferente.

Embora os PCN apontem a matemática como uma ciência presente em quase todas as atividades humanas, os estudantes ainda têm grandes dificuldades de perceber suas aplicações. Os motivos para isso são diversos, destaca-se a deficiência de discussões mais voltadas às práticas pedagógicas nos cursos de licenciatura em matemática. Certamente ainda há muito o que se fazer para se reverter este quadro e, nesse contexto, ações como as do Pibid têm sido muito importantes. O programa em si 
já apresenta-se como uma renovação para as licenciaturas de todo o país, sendo um importante elo entre os dois contextos, a formação inicial do professor e seu contato com a sala de aula, o que faz com que os estudantes bolsistas (graduandos) já problematizem discussões e criem estratégias para resolver problemas cotidianos no ensino de matemática, além disso o auxílio aos alunos do ensino médio é imediato.

Dando continuidade à oficina, foi necessário fazer uma pequena revisão de divisão e multiplicação de frações com denominadores iguais e diferentes. Só assim os alunos foram capazes de responder às perguntas feitas durante a oficina sem o uso de calculadora.

Os alunos fizeram os cálculos solicitados com grande facilidade após a explicação da fórmula, pois os que desconheciam a forma de usá-la passaram a conhecê-la após a explicação. A única dificuldade foi o fato de os cálculos de fatoração serem muito grandes, como nem todos os alunos possuíam calculadoras, tiveram que trabalhar em dupla, promovendo o espírito de equipe, já que estavam sendo estimulados para que os cálculos fossem feitos pela dupla e não que um estudante se "escorasse" no outro.

\section{Conclusão}

A oficina Ensinando probabilidade explorando as loterias foi uma forma de ensinar probabilidade usando situações do cotidiano através do uso dos jogos de loterias.

O uso de uma situação do cotidiano, neste caso, o uso da mega-sena, despertou o interesse dos alunos para aprender probabilidade. Os questionamentos iniciais foram uma das formas de motivação.

Uma proposta deste trabalho é de que esta oficina seja usada em sala de aula, nas aulas regulares, pois, na experiência de sua aplicação, percebeu-se que ela pode servir como um método que possibilita proporcionar um aprendizado mais significativo para os alunos, de uma forma lúdica, despertando o interesse e a atenção, deixando-os mais curiosos. Talvez, assim, além de popularizar o estudo da probabilidade, seja possível 
conseguir uma considerável evolução no desempenho dos alunos, melhorando os baixos resultados obtidos em avaliações internas e externas.

\section{Referências Bibliográficas}

BOYER, C. B. História da matemática. São Paulo: Edgard Blucher, 1996.

BRASIL. Parâmetros Curriculares Nacionais. Ensino médio e tecnológico. Brasília: MEC/SEF, 2000.

CAIXA ECONÔMICA FEDERAL: banco de dados. Disponível em: <http://loterias.caixa.gov.br/wps/portal/loterias/landing/megasena\#wp_arrecadacao>. Acesso em: 28 set. 2016.

FRAGA, R. R. O estudo das loterias: uma abordagem motivadora e facilitadora para aprendizagem de probabilidade no Ensino Médio. 2013. 67f. Dissertação (Mestrado Profissional em Matemática) - Instituto de Matemática Pura e Aplicada- Rio de Janeiro: IMPA, 2013.

GRANDO, R. C. O Jogo e suas possibilidades metodológicas no processo ensinoaprendizagem da matemática. 1995. 159f. Dissertação (Mestrado) - Faculdade de Educação, Universidade Estadual de Campinas, Campinas: 1995.

LIMA, E. L. et al. Temas e Problemas Elementares. Coleção do Professor de Matemática. Rio de Janeiro: SBM, 2006.

MORGado, A. C. et al. Análise Combinatória e Probabilidade. Rio de Janeiro : Coleção do Professor de Matemática. Rio de Janeiro: SBM, 1997.

MOURA, M. O. O jogo e a construção do conhecimento matemático. (Série Ideias, 10). São Paulo: FDE, 1992. Disponível em: <http://www.crmariocovas.sp.gov.br/pdf/ ideias_10_p045-053_c.pdf>. Acesso em: 10 nov. 2016. 